Original Research Paper

\title{
Developing a Prototype for Sun Tracker System Based on IoT: Controlled by Mobile App and Online Database Monitoring
}

\author{
${ }^{1,5}$ Ismail Ismail Yusuf Panessai, ${ }^{1}$ Muhammad Modi bin Lakulu, ${ }^{2}$ Siva Kumar A/L Subramaniam \\ ${ }^{3}$ Ahmad Fadli Saad, ${ }^{4}$ Muhd Ibrahim Muhamad Damanhuri and ${ }^{5}$ Nur Iksan Yusuf \\ ${ }^{I}$ Department of Computing, Faculty of Art, Computing and Creative Industry, \\ Universiti Pendidikan Sultan Idris, 35900 Tanjong Malim, Malaysia \\ ${ }^{2}$ Department of Electronic and Computer Eng., Universiti Teknikal Malaysia Melaka, Melaka, Malaysia \\ ${ }^{3}$ School of Computing and Creative Media, University College of Technology Sarawak, Sarawak, Malaysia \\ ${ }^{4}$ Department of Chemistry, Faculty of Science \& Mathematics, Universiti Pendidikan Sultan Idris, \\ 35900 Tanjong Malim, Malaysia \\ ${ }_{5}^{5}$ Lamintang Education and Training (LET) Centre, Buana Impian, Blok B1 No. 27 \& 28, \\ Kota Batam, Kepri, Indonesia
}

Article history

Received: $31-12-2018$

Revised: 31-01-2019

Accepted: 11-02-2019

Corresponding Author: Ismail Ismail Yusuf Panessai, Department of Computing, Faculty of Art, Computing and Creative Industry, Universiti Pendidikan Sultan Idris, 35900 Tanjong Malim, Malaysia Email: ismail.lamintang@yahoo.com ismailyusuf@fskik.upsi.edu.my

\begin{abstract}
IoT (Internet of Things) has become a separate research field since the development of internet technology and other communication media. IoT optimizes several tools such as sensor media radio frequency identification, wireless sensor networks and other smart objects that allow humans to easily interact with all devices connected to the internet network. The purpose of this research is to build an IoT-based solar cell tracker which can be controlled through mobile Apps and the data can be read anywhere as long as there is an internet network. In this research used LDR sensor, DHT11 sensor, Voltage sensor and MPU6050 sensor to optimize the performance of the proposed solar cell tracker system. The control system is built using an Appinventor that allows the system to be controlled via cellular phone from a distance. All sensors will be connected via Arduino and realtime data can be viewed through the Thinger.Io web page using Raspberry and mini LCD. ESP8266 NODE MCU microcontroller is used for a Wi-Fi connection. The results of this study indicate that the voltage value generated by dynamic solar cell tracker is greater than the static solar cell tracker. Dual axis sun tracker devices that are built using four LDRs produce an average voltage of 19.40 Volt when the sunny weather, 18.05 Volt when the cloudy weather and 13.60 Volt when the rainy weather.
\end{abstract}

Keywords: IoT, Solar Cell, Tracker, Dual Axis, Arduino, Raspberry, Sensor

\section{Introduction}

The community's need for energy is currently increasing, along with the increase in population and technological advancement (Ranabhat et al., 2016; Lee et al., 2009). Energy use until 2025 is still dominated by fossil fuels namely petroleum, natural gas and coal (Bryan et al., 2011; Barbose et al., 2014). Although petroleum reserves, natural gas and coal are still quite high, the use of these fuels is a source of carbon dioxide emissions (Samrat et al., 2014).

Also, with other energy sources such as water and wind. The use of water energy is often an obstacle when the dry season arrives where water sources used as plants often recede and water discharge is reduced so that energy generation cannot operate optimally. Meanwhile, wind energy is rather complicated because the construction requires certain regional topologies.

Therefore, the choice of energy sources that are very suitable for tropical regions that get sunlight throughout the year such as in Malaysia, Indonesia, Papua New Guinea and the areas that are on the equator is solar energy. Even though there is a rainy season, it can be said that sunlight will be available throughout the year. Sunlight is a natural energy source that is available as alternative energy that is clean, non-polluting, safe and with unlimited supplies. 


\section{Solar Cell}

One of the technological efforts to utilize solar energy is to use solar cells. Solar cells are a collection of photovoltaic cells that can convert sunlight into electricity. Solar cells will produce electrical energy according to the intensity of light received from the sun's rays (Alexandru, 2013; Bradbury et al., 2016).

Conventional solar cells work using the principle of $\mathrm{p}$-n junction, which is the junction between the p-type semiconductor and the n-type. This semiconductor consists of atomic bonds in which there are electrons as a basic constituent. N-type semiconductors have excess electrons (negative charges) while p-type semiconductors have excess holes (positive charge) in their atomic structure. The condition of the excess electrons and holes can occur by doping the material with a dopant atom. As an example, to get a P-type silicon material, silicon is doped by boron atoms, whereas to get an N-type silicon material, silicon is doped by phosphorus atoms.

The role of these $p-n$ junctions is to form an electric field so that electrons (and holes) can be extracted by contact material to produce electricity. When the p-type and n-type semiconductors are contacted, the excess electrons will move from the n-type semiconductor to the p-type to form a positive pole in the n-type semiconductor and the negative pole on the p-type semiconductor instead. As a result of the flow of electrons and holes, an electric field is formed which when the sun's light on the PN of these junctions will push electrons to move from the semiconductor to the negative contact, which is then used as electricity and instead the hole moves towards the positive contact waiting for the electron to come, like illustrated in Fig. 1.

Various techniques are used in maximizing the absorption of sunlight, including image processing techniques in Lee et al. (2013) study, attitude determination in Rufino and Grassi (2009) research, altazimuthal tracker in Merlaud et al. (2012) study, multi-robot systems in Rodr'iguez-Canosa et al. (2014) study, VOC algorithms in Antolín et al, (2017) study and others technique used in other related study such as in Zhu and Zhao (2018), Tharamuttam and $\mathrm{Ng}$ (2017) and Wang and Lu (2013) studies.

\section{Internet of Things}

The Internet of Things (IoT) is a concept where everything around us can communicate with each other through an internet network. The initial idea of IoT was first raised by Kevin Ashton in 1999 (Skouri et al., 2016).

There are two types of devices that are often used in applying IoT, namely Arduino and Raspberry Pi (Scott, 2015; Horan, 2013; Upton, 2015).

\section{Arduino}

Arduino is one of the AMEGA 328 (datasheet) microcontrollers. It has 14 input pins from the digital output where the 6 input pins can be used as PWM outputs and 6 analogue input pins, $16 \mathrm{MHz}$ crystal oscillator, USB connection, power jack, ICSP header and reset button.

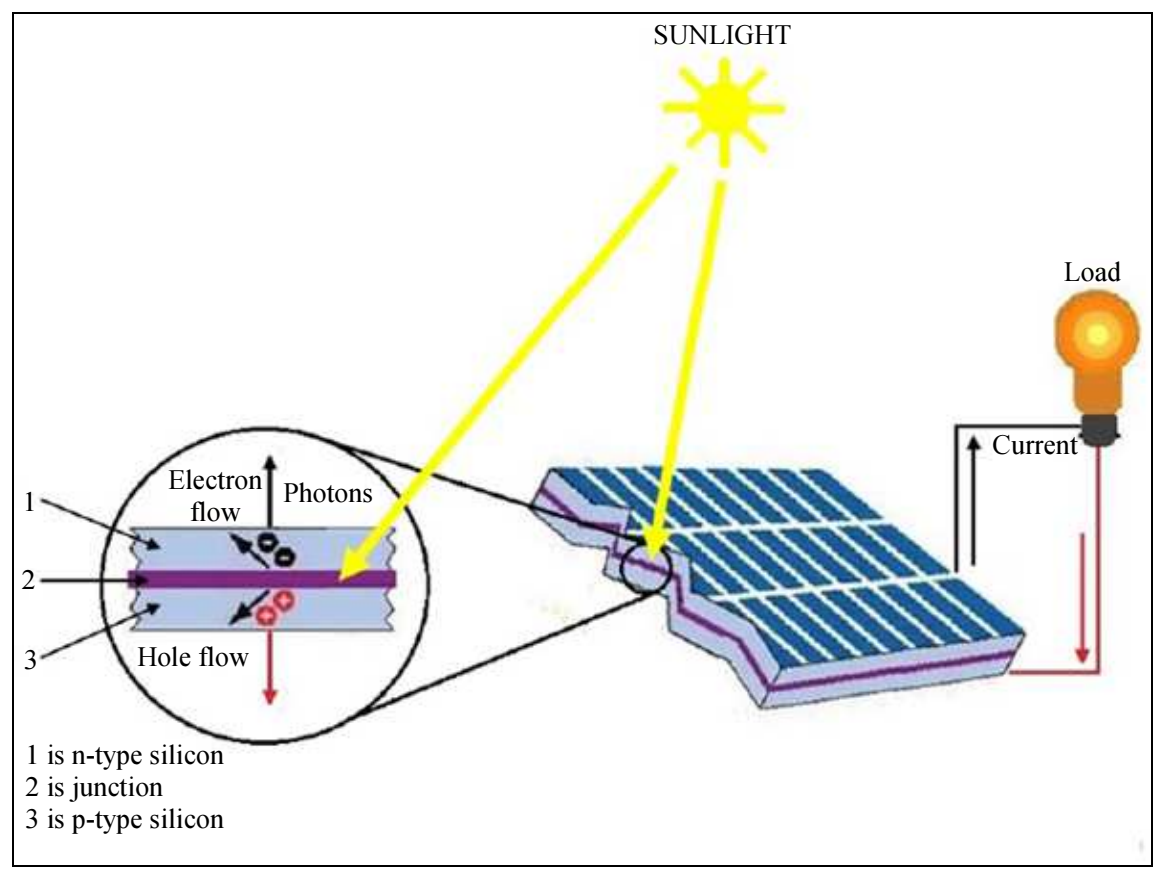

Fig. 1: Illustration of how solar cells work with the p-n junction principle 


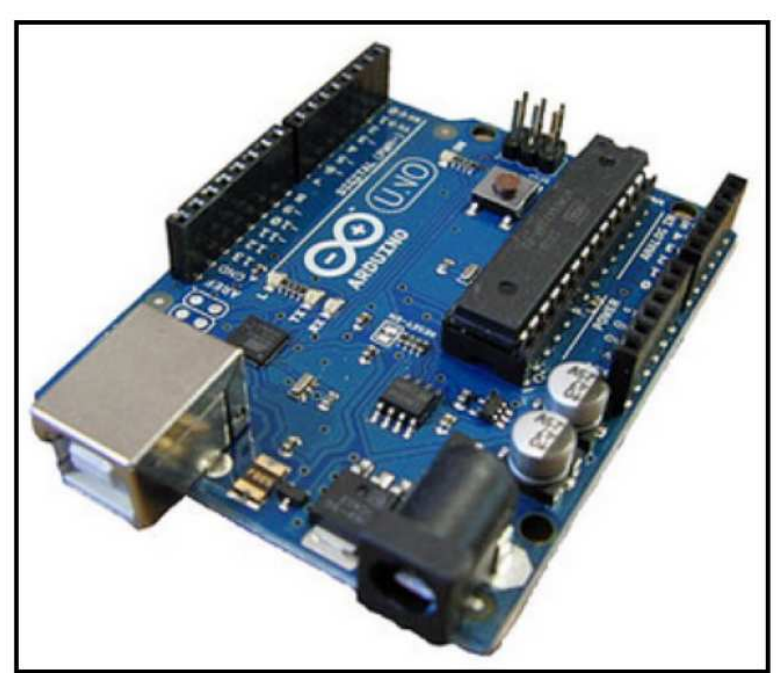

Fig. 2: Arduino, Adopted from Zhu and Zhao (2018)

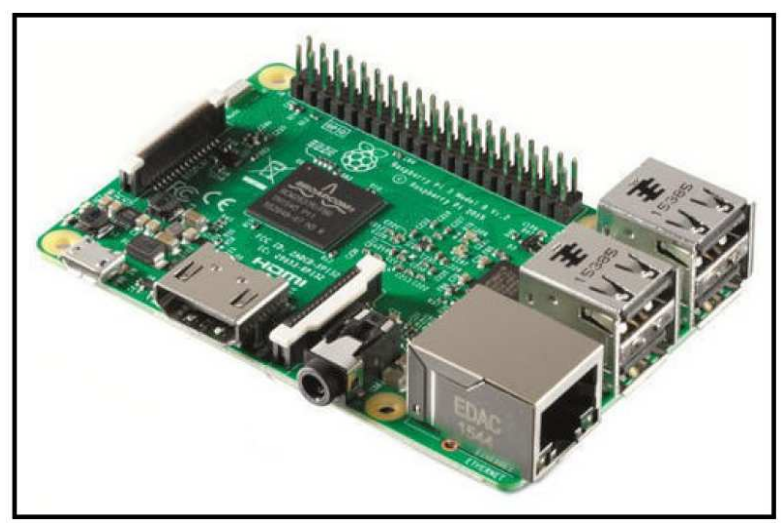

Fig. 3: Raspberry Pi Type B+, Adopted from Tharamuttam and $\mathrm{Ng}(2017)$

Arduino as shown in Fig. 2, is based on Embedded System so that Arduino does not need an Operating System in operation. And, Arduino doesn't need a downloader to program it. Arduino supports $\mathrm{C} / \mathrm{C}++$ Language. To program Arduino is enough to connect it to a computer via USB and activate the Arduino IDE (Integrated Development Environment).

In its specifications, Arduino has $32 \mathrm{~KB}$ Flash memory, 2 KB SRAM, 1 KB EEPROM and has a clock speed of $15 \mathrm{MHz}$. These specifications are sufficient for a microcontroller to meet the needs of a project, but users cannot write programs more than $32 \mathrm{~KB}$.

Arduino is very powerful in supporting other hardware devices such as switches, sensors, other microcontrollers and so on. Arduino also has a variety of Shields that have various functions such as shields that function as Wi-Fi, LCD, Bluetooth modules and so on.

\section{Raspberry Pi}

Raspberry Pi as shown in Fig. 3, is a Single Board Computer, so it can be said that Raspberry $\mathrm{Pi}$ is a mini computer that can be used as a computer that is commonly used. Raspberry $\mathrm{Pi}$ requires Linux in operation.

Raspberry Pi Has 4 Slots in B + type, HDMI Port, LAN Port, Jack and Video Audio Port (RCA) and Mini USB Port as Charger for Raspberry Pi. To operate the Raspberry $\mathrm{Pi}$ needed is an SD card to install the operating system, mouse, keyboard and monitor that has an HDMI input.

In Operation, Raspberry Pi uses Python and Perl languages in programming. The Raspberry Pi has two models namely the A model and the $\mathrm{B}$ model. The difference between the $\mathrm{A}$ and $\mathrm{B}$ models lies in the memory used, Model A uses 256MB of memory and the 512MB B model. Besides that, the B model has also been equipped with an Ethernet port (network card) that is not found in the A model. The Raspberry Pi design is based on the Broadcom BCM2835 Systemon-a-chip, which has embedded the ARM1176JZF-S processor with $700 \mathrm{MHz}$, Video Core IV GPU and 256 Megabytes of RAM (model B).

To improve its performance, the Raspberry $\mathrm{Pi}$ is supported by several additional shields for example Camera Module, LCD Display Module and others. Data storage on the Raspberry Pi is designed not to use hard disks or solid-state drives but instead relies on SD memory cards for long-term boot and storage.

\section{Comparison between Arduino and Raspberry Pi}

The strengths and weaknesses of the two depending on what they are used for. If the goal is to use high efficiency real-time control, then Arduino is better. But Raspberry Pi has advantages, it can do all the functions of a computer. Whether it's programming, multimedia, or surfing in cyberspace. Apart from that, by using Raspberry Pi, the user can control the project through the Linux GUI found on the Raspbian OS, so that testing on a project can be done easily.

For example, when creating a robot project, the Arduino is best used because it has a higher level of precision compared to Raspberry Pi. That is because Arduino uses Firmware in its operation, unlike Raspberry Pi which uses the Operating System. Raspberry Pi that uses the OS in its operation will take longer than Arduino. That's because also because the resources contained in Raspberry Pi tend to prioritize all the processes that are in the OS.

\section{Proposed for Solar Tracking Model}

\section{Solar Tracking based on IoT}

In its application, solar panels are placed statically where the solar panel only leads to one particular direction so that the absorption of sunlight intensity cannot be performed optimally and results in the 
maximum power produced. To utilize solar energy maximally, the solar panel must follow the direction of sunlight. The greater the intensity of sunlight captured by the solar panel, the greater the electrical power produced. Therefore, a control device is made that allows solar panels to move in the direction of the sun's crossing from east to west.

This research uses a solar tracker consisting of horizontal axis tracker and vertical axis tracker. The rotation axis for the horizontal axis tracker is mounted in a horizontal position with the ground, where horizontal axis tracker works more effectively at low latitudes. The rotation axis for vertical axis tracker is made perpendicular to the ground. This vertical axis tracker moves from East to West and is more effective at high latitudes compared to horizontal axis tracker.

The use of these two types of tracker will make the controller's performance increase. The movement of the two trackers will be controlled through a mobile application built in the AppInventor platform. System control can be done from anywhere without having to be near the system. A mini Liquid Crystal Display (LCD) 7" inch size monitor that is activated using a microcomputer raspberry pi serves to display information on the reading of the temperature, voltage and light intensity obtained by solar panels. This information is also displayed in real time at http://thinger.io so database monitoring can be done anywhere via the web.

A Model proposed for solar tracking as shown in Fig. 4.

\section{Working Principles}

The system is equipped with a 12 Volt power supply. The power supply serves to provide energy to microcontrollers and other devices. There are diodes and potentiometers installed between the solar panel and the battery. The diode serves to prevent the battery from supplying the solar panel. And the potentiometer connected to the Arduino serves to regulate the sensitivity of the solar tracker.

In addition, the system is equipped with a battery control unit, which is a device that functions to decide the charging between the solar module and the battery when it has reached the maximum threshold, which is 13.65 Volts (in this case a 12 Volt battery capacity) and disconnect between battery and load when the battery capacity reaches the minimum threshold, which is 10.5 Volts.

Block diagram of the model proposed for solar tracking shown in Fig. 5.

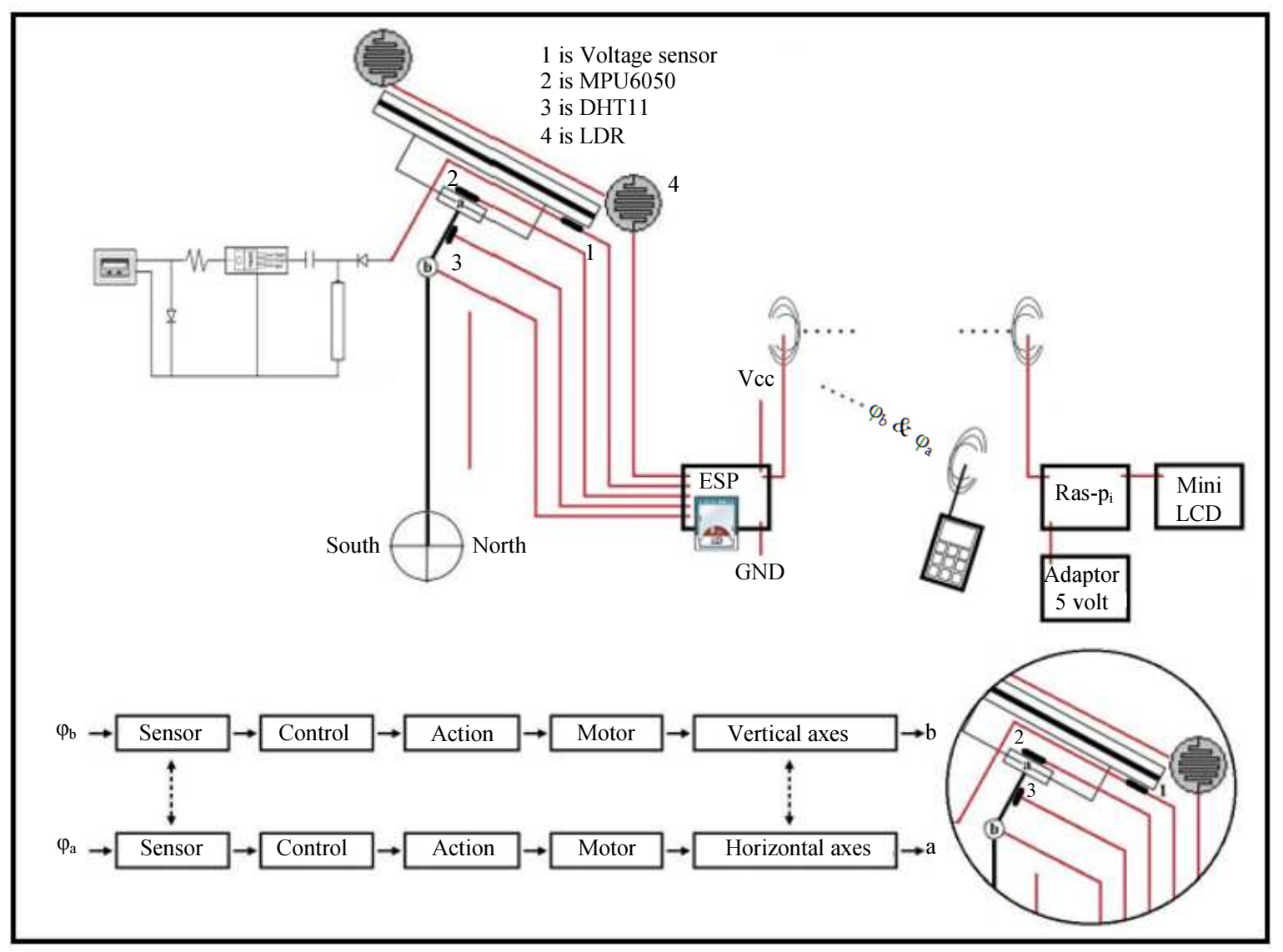

Fig. 4: A Model proposed for solar tracking: Solar tracker based on IoT 


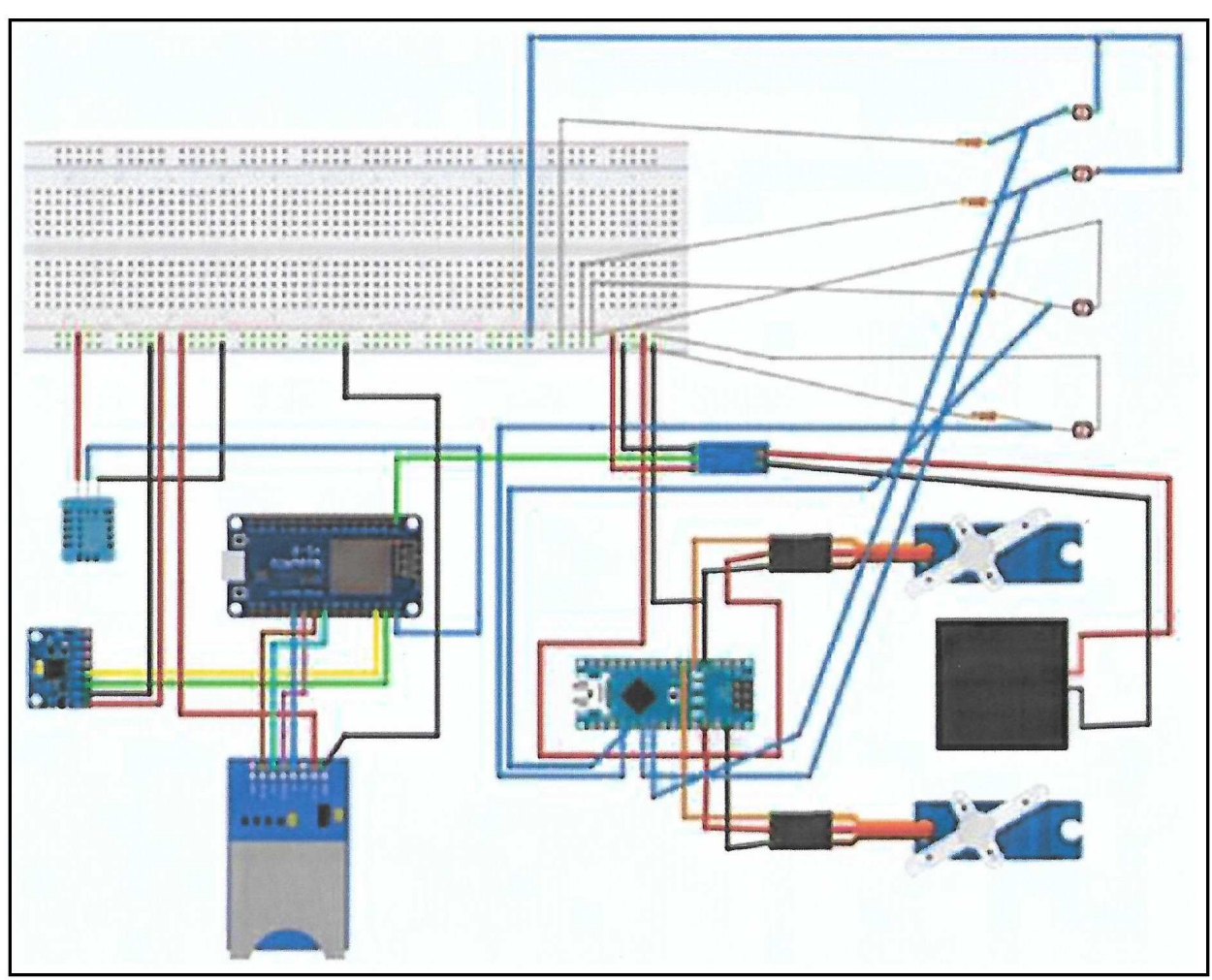

Fig. 5: Network of physical devices

The working principle of the system is that the batteries and photovoltaic modules work together to provide electrical energy to the load. Electrical energy can be generated directly from the photovoltaic module during the day and energy is taken from the battery at night. Energy can be taken from batteries and photovoltaic during cloudy weather. All cannot be separated from the $\mathrm{BCU}$ (Battery Control Unit) function as a regulator.

When the system is first turned on, the system will initiate the solar parts tracking system, after the initialization process, the microcontroller is active. Engineering can then control the position of the panel remotely through mobile apps. After obtaining a position that allows solar panels to absorb sunlight optimally, the system will absorb solar energy. After maximum energy is obtained, the energy is converted into electrical energy and then stored in the battery and can also be directly used to charge (charger).

During the day, the sun shines by removing radiation energy through light waves. With photovoltaic modules, the light energy from solar radiation is converted into electrical energy. If the voltage on the module is greater than the battery voltage, the charging current occurs to the battery. The battery voltage will continue to increase linearly with the charging time. If the battery voltage has reached the maximum threshold set, which is 13.65 Volts, then BCU will disconnect between the photovoltaic module and the battery.
At night, there is no energy produced by the photovoltaic module, which automatically supplies energy to the load is the battery. If you use too much battery energy, the battery voltage will decrease as the battery energy decreases. If the battery voltage drops past the minimum threshold set, which is 10.5 volts, then the load will automatically die which is marked by a disconnection between the battery and the load.

\section{Experiment Design}

There are several important things for the solar tracking that are proposed excluding Raspberry PI and Arduino, namely:

1. Solar Cell

2. Tracking

3. Power Supply

4. Motor Servo

5. Mini LCD

6. Light Dependent Resistor

7. Temperature Sensor DHT11

8. Microcontroller ESP8266 NODE MCU

9. MPU6050

10. Micro SD Card - ESP

11. Voltage Sensor VCC $<25$

12. Analog to digital converter

13. AppInventor

14. ThingerIo 


\section{Solar Cell}

Figure 6 shows the 5 Volt DC solar panel prototype used in this study. A 5 Volt DC solar panel has a measured maximum voltage of 6.5 volts and a minimum voltage of 0 volts. The solar panel has two cables, namely a positive cable and a negative cable that will flow in a direct electric current (DC current). Simply put, the working principle is when the solar panel is exposed to sunlight, it will produce voltage.

\section{Tracking}

Azimuthal dual-axis system used for this research, where daily motion is made by rotating the module around the vertical axis so that it is necessary to continuously combine the vertical rotation with an altitudinal motion around the horizontal axis.
Figure 7 shows the sensor system of the proposed and called as four-quadrant sensor system.

\section{Power Supply}

The Power Supply circuit is the main series of microcontroller-based prototype solar tracking systems. The Power Supply circuit connects the resource with the entire circuit. The power source used comes from a battery with a voltage of 5 volts.

\section{Motor Servo}

Figure 8 shows the servo motor used in this research. A servo motor is a rotary device or actuator (motor) designed with a closed loop feedback control system (servo) so that it can be set-up or adjusted to determine and ensure the angular position of the motor output shaft.

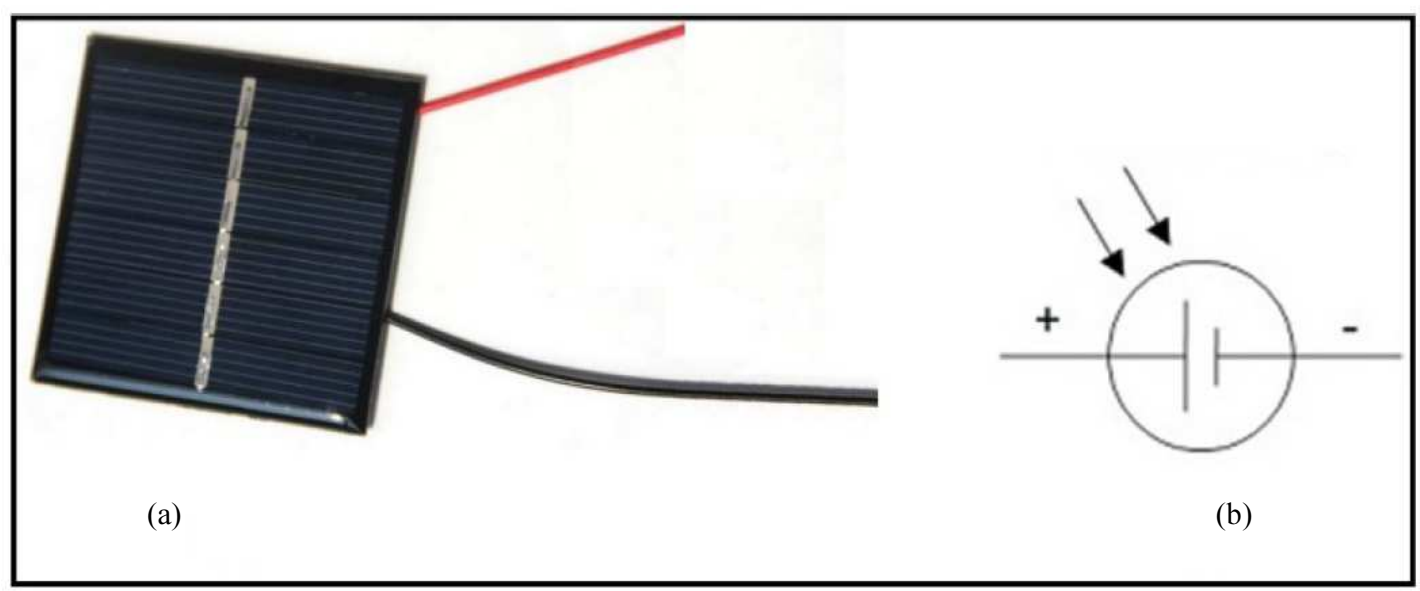

Fig. 6: (a) Solar Cell 5 Volt DC (b) Symbol for solar cell

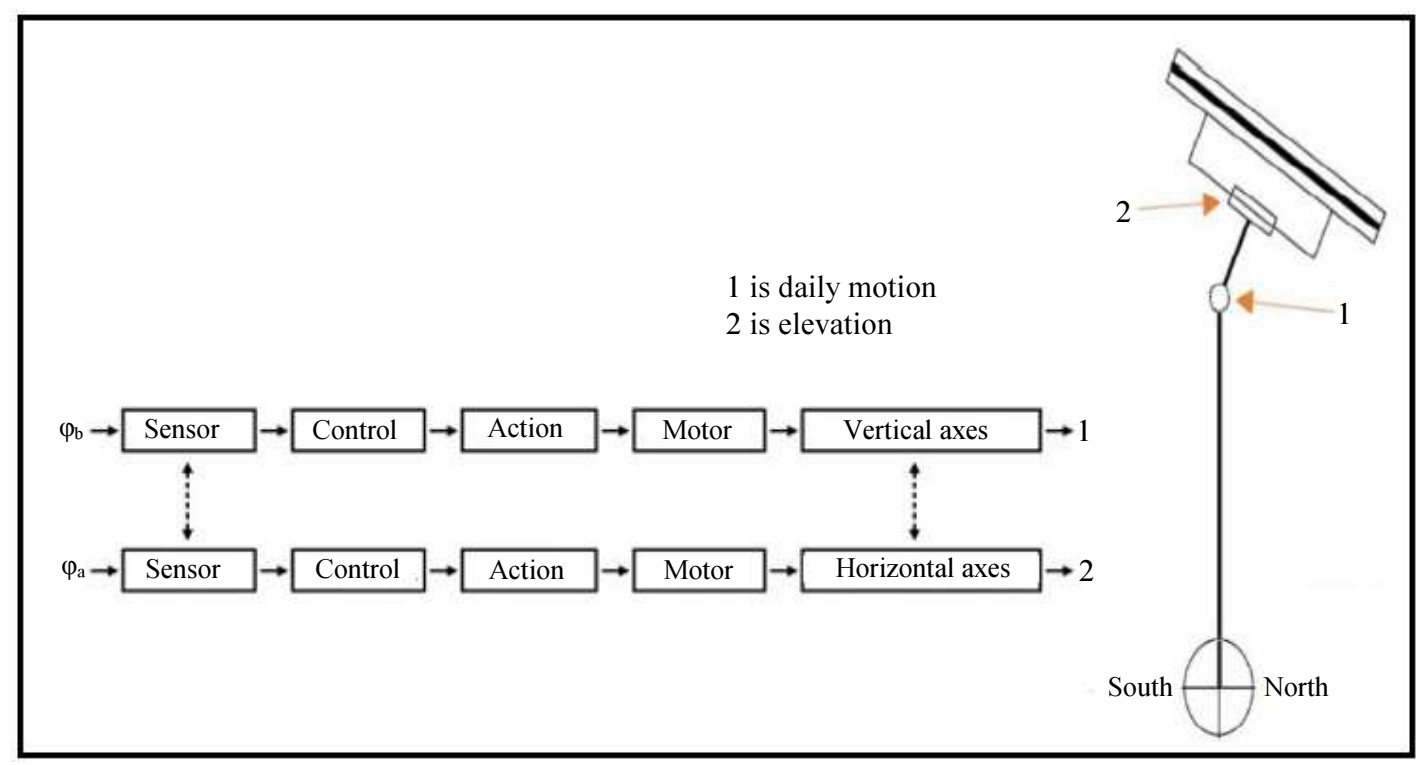

Fig. 7: Four Quadrant Sensor system: Azimuth dual-axis 
The servo motor used in this study is a DC servo motor with standard rotation. DC servo motor is a device that consists of a DC motor, a series of gears, a control circuit and a potentiometer. A series of gears attached to the DC motor shaft will slow down the shaft rotation and increase the servo motor torque, while the potentiometer with resistance changes when the motor rotates serves as a determinant of the position limit of the servo motor shaft rotation. The standard rotation servo motor $\left(180^{\circ}\right.$ servo rotation) is a servo motor with its output shaft rotation limited to $90^{\circ}$ to the right and $90^{\circ}$ to the left.

\section{Mini $L C D$}

This system uses a 7" inch mini Liquid Crystal Display (LCD) as shown in Fig. 9, which is activated using a raspberry pi microcomputer. Mini LCD will display information about reading the slope, temperature, voltage and light intensity.

\section{Light Dependent Resistor}

In this research, four LDR were used to determine the resistance value, in which the LDR was installed in each corner of the solar cell.

Light Dependent Resistor (LDR) as shown in Fig. 10, is a type of resistor whose resistance value or resistance value depends on the intensity of the light it receives. The value of LDR resistance will decrease when bright light and value will become high if in dark conditions. In other words, the function of the LDR is to deliver electric current if it receives a certain amount of light intensity (Light Condition) and inhibits an electric current in dark conditions. The rise and fall of the resistance value will be proportional to the amount of light it receives.

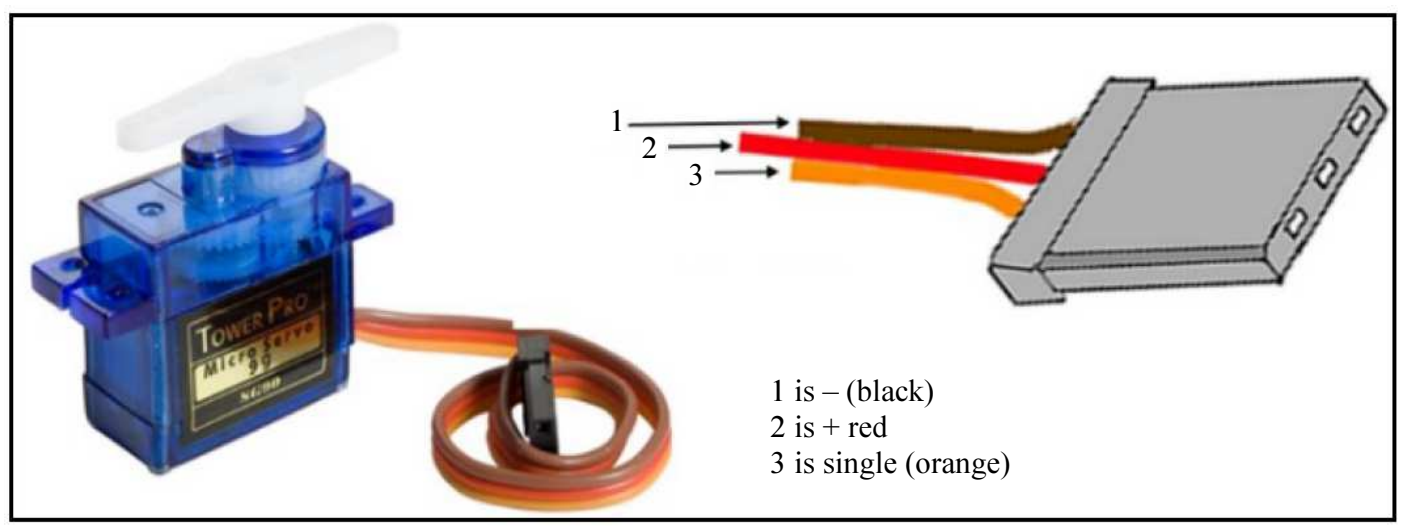

Fig. 8: Motor Servo series

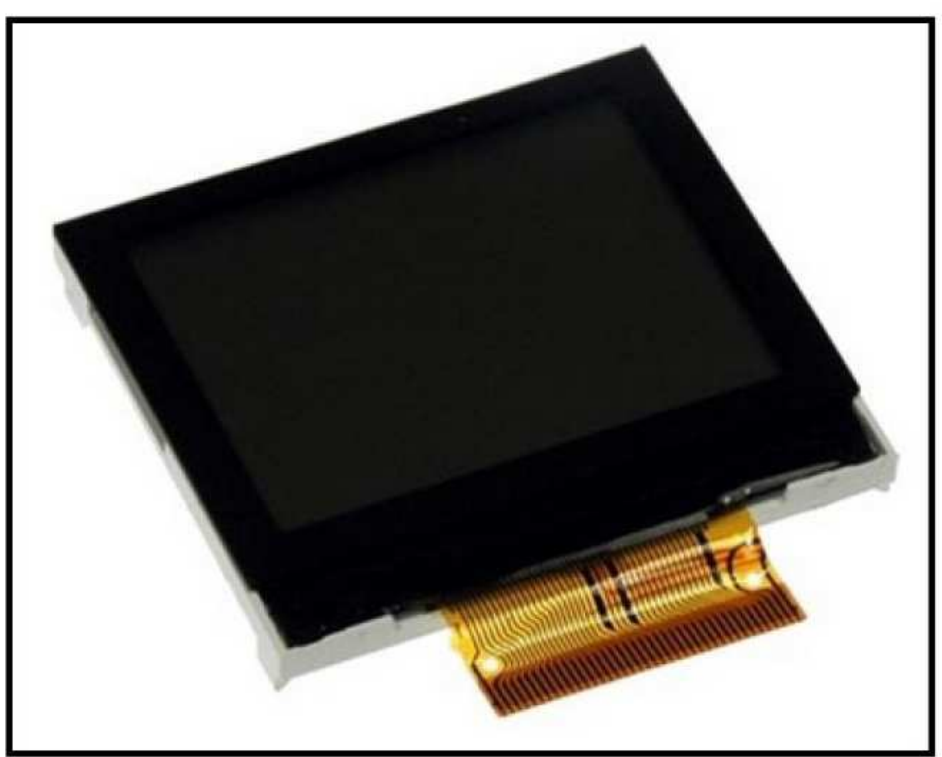

Fig. 9: Mini LCD Connected to Raspberry Pi 


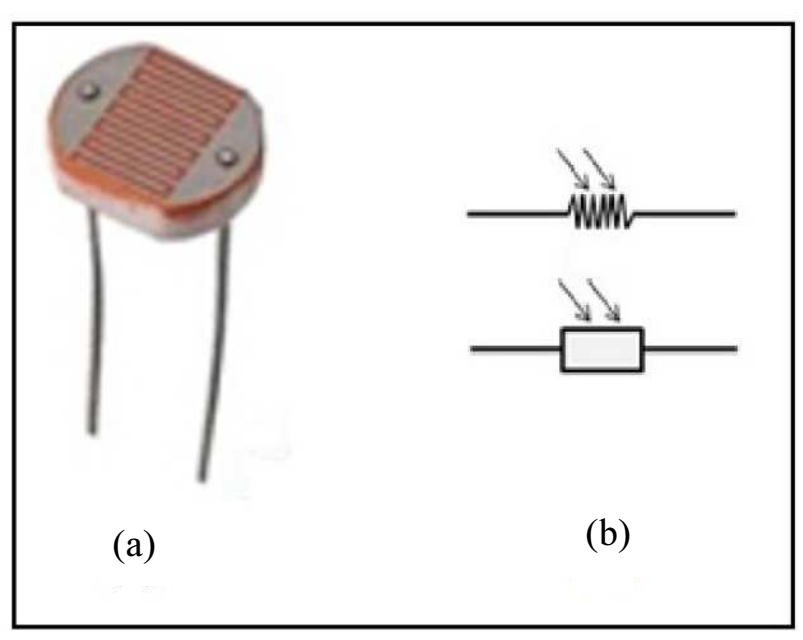

Fig. 10: (a) LDR (b) Symbol for LDR

\section{Temperature Sensor DHT11}

The DHT11 sensor is a sensor module that functions to sensing temperature and humidity objects that have the analog voltage output that can be further processed using a microcontroller. Figure 11 shows DHT11 used in this research.

The DHT11 sensor has three pins, namely:

- $\quad$ The VCC pin is connected to a source voltage of 3.3 volts or 5 volts $\mathrm{DC}$

- Data pins are connected with digital pins found on the microcontroller

- The ground pin is connected to the ground pin on the microcontroller

\section{Microcontroller ESP8266 NODE MCU}

This study uses the ESP8266 Microcontroller NODE MCU for Wi-Fi connection, as shown in Fig. 12. ESP8266 is a Wi-Fi module that functions as an additional microcontroller like Arduino so that it can connect directly with Wi-Fi and make TCP/IP connections. This module requires a power of around $3.3 \mathrm{v}$ with three Wi-Fi modes, namely Station, Access Point and Both. This module is also equipped with processor, memory and GPIO where the number of pins depends on the type of ESP8266 used. This module can stand alone without using any microcontroller because it already has equipment like a microcontroller.

Node MCU ESP8266 is a development derivative module of the ESP8266 family type EST-12 IoT (Internet of Things) platform module. Functionally this module is almost similar to the Arduino module platform, but what distinguishes it is devoted to "Connected to the Internet".

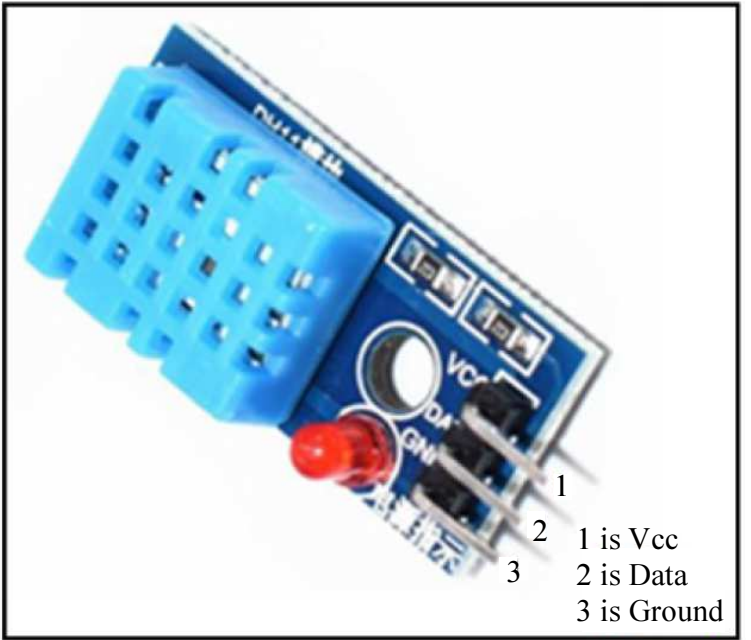

Fig. 11: Sensor for temperature: DHT11

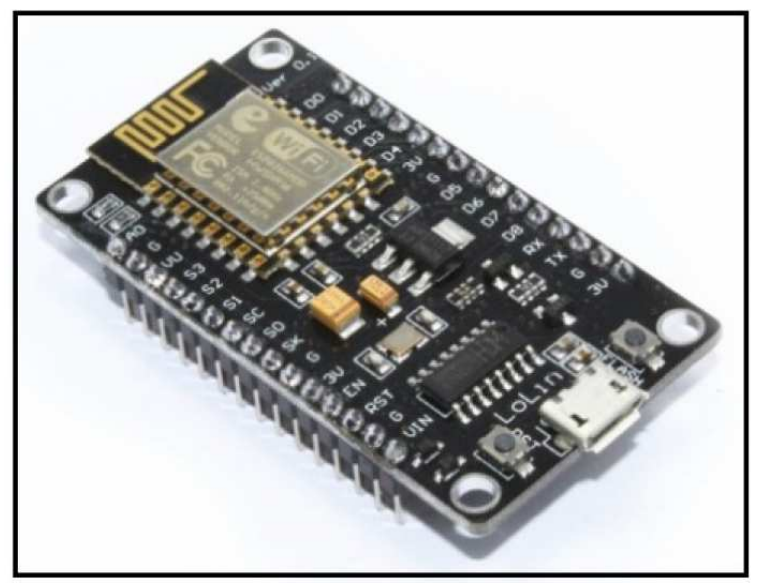

Fig. 12: Microcontroller ESP8266 NODE

\section{MPU6050}

In this research MPU6050 sensor was used. MPU6050 as shown in Fig. 13, is a sensor used to determine slope. The MPU6050 sensor is able to read angle tilt based on data from the accelerometer sensor and gyroscope sensor.

The MPU6050 sensor has 8 pins, including:

1. Pin Vcc, connected to a 3 Volt pin

2. Pin GND, connected to a GND ESP pin

3. Pin SDA connected to a D2 ESP pin

4. Pin SCL connected to a D1 ESP pin

5. Four pins no need connected to any pin

\section{Micro SD Card - ESP}

The Micro SD Card as shown in Fig. 14, communicates with ESP using SPI. The Micro SD Card library is "SD.h", which is provided by Arduino by default when installing the Arduino IDE Software. The 
library "SD.h" will be used to Read and Write on a Micro SD card.

\section{Voltage Sensor}

The working principle of the voltage sensor module is based on the principle of suppression of resistance and can make the input voltage decrease by 5 times the original voltage.

Voltage Sensor VCC $<25$ is used in this research. The form of a voltage sensor module as shown in Fig. 15.

\section{Analog to Digital Converter}

The An analogue to digital converter (ADC) circuit converts the output of the analogue circuit to digital $\operatorname{logic}(1 / 0)$ with 5 Volt DC $V_{\text {reff. }}$ By comparing $V_{\text {reff, }} V_{\text {in (+) }}$ and $V_{\text {in (-) }}$ it will get data in the form of digital signals calculated based on Equation 1:

Vout $=\frac{\left(V_{i n(+)}-V_{i n(-)}\right)}{255}$
The results of these calculations are then converted into binary data that will be issued through the ADC port as information on the amount of voltage.

\section{AppInventor}

The controller is built using the AppInventor platform which is activated by logging in at http://ai2.appinventor.mit.edu. Front page of the AppInventor shown in Fig. 16. The control is based on mobile apps where engineers need to enter their ID and Password to be active in the system. In this study, angles were determined at $0,30,90,120$ and 180 for each horizontal and vertical axis tracker.

\section{ThingerIo}

ThingerIo is used to display information about reading the slope, temperature, voltage and light intensity. This information will be displayed in real time in the form of a chart or graphic. ThingerIo. Activated via https://console.thinger.io. Front page of the ThingerIo shown in Fig. 17.

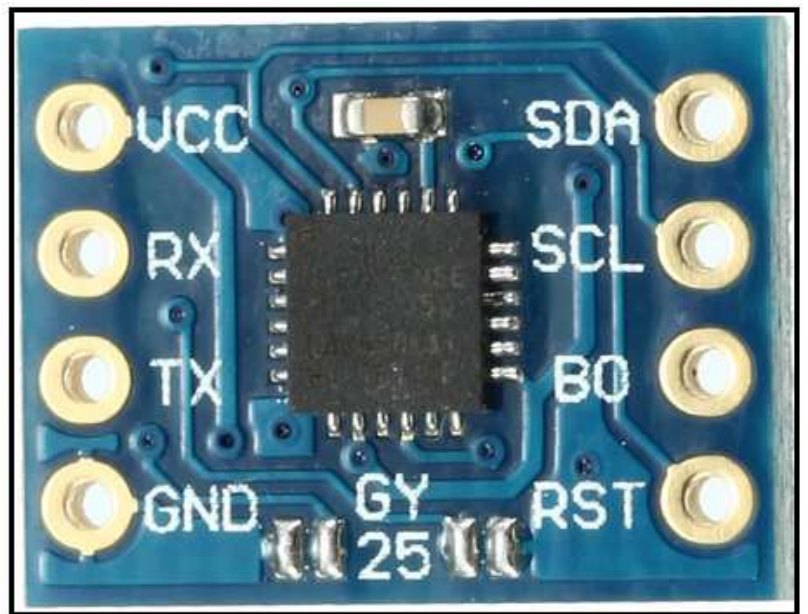

Fig. 13: MPU6050

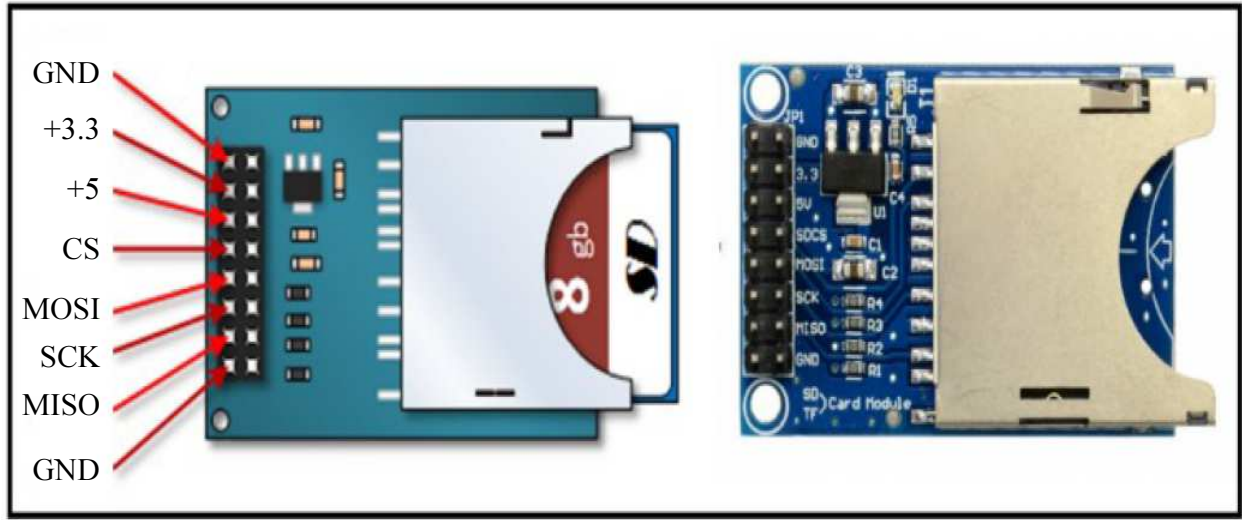

Fig. 14: ESP -SPI 


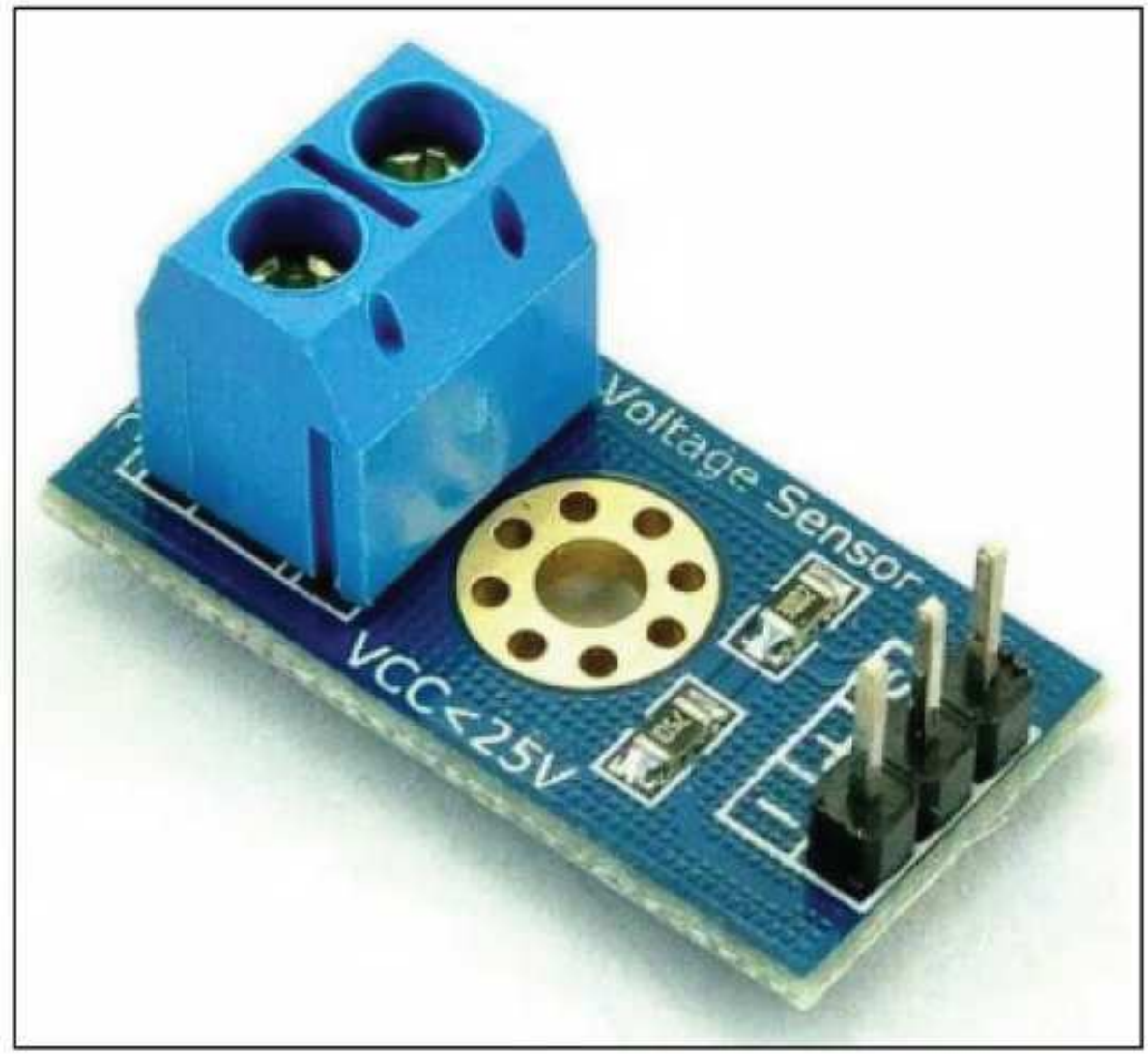

Fig. 15: Voltage sensor $\operatorname{VCC}<25$

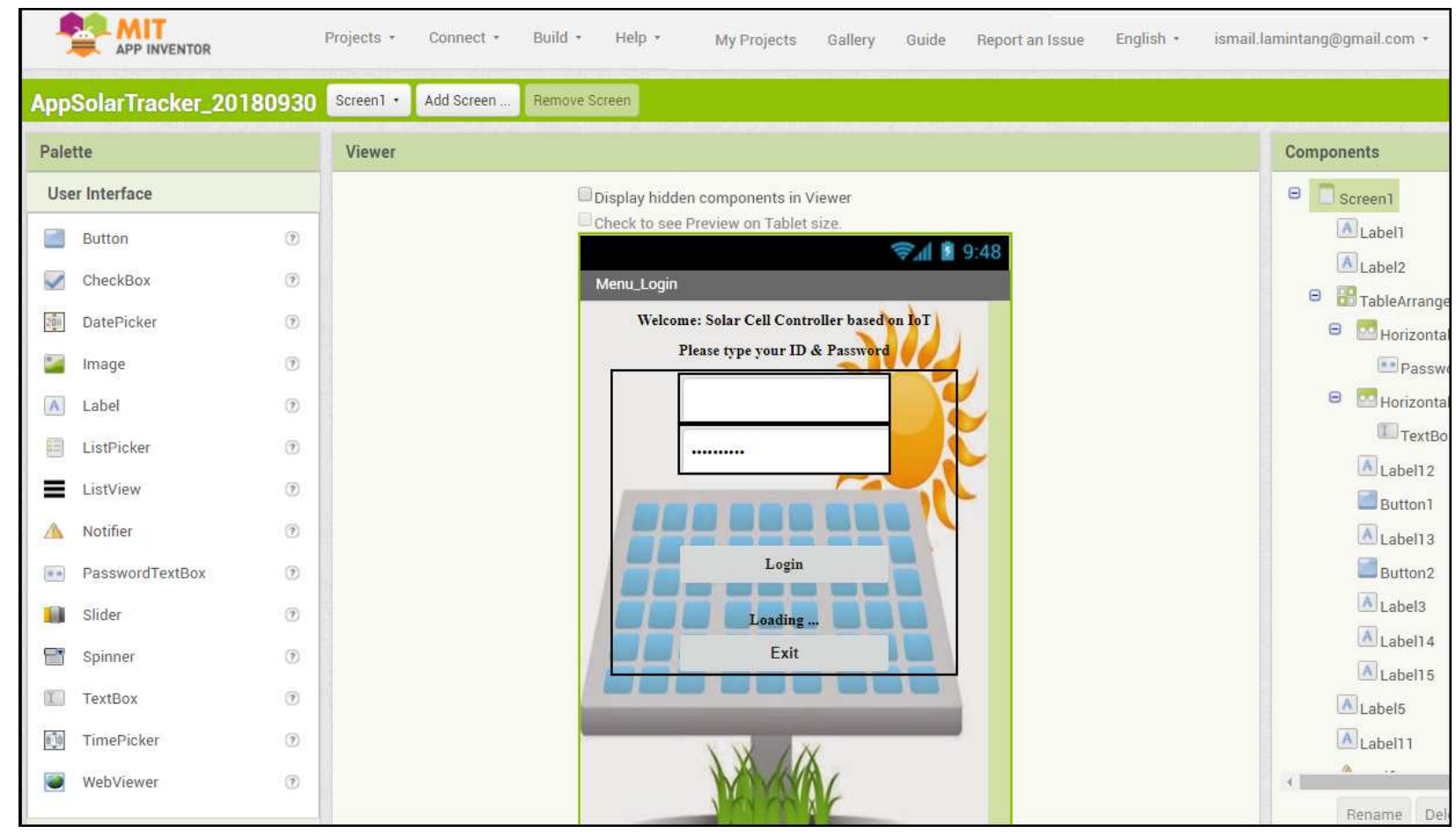

Fig. 16: Controller built in AppInventor platform 


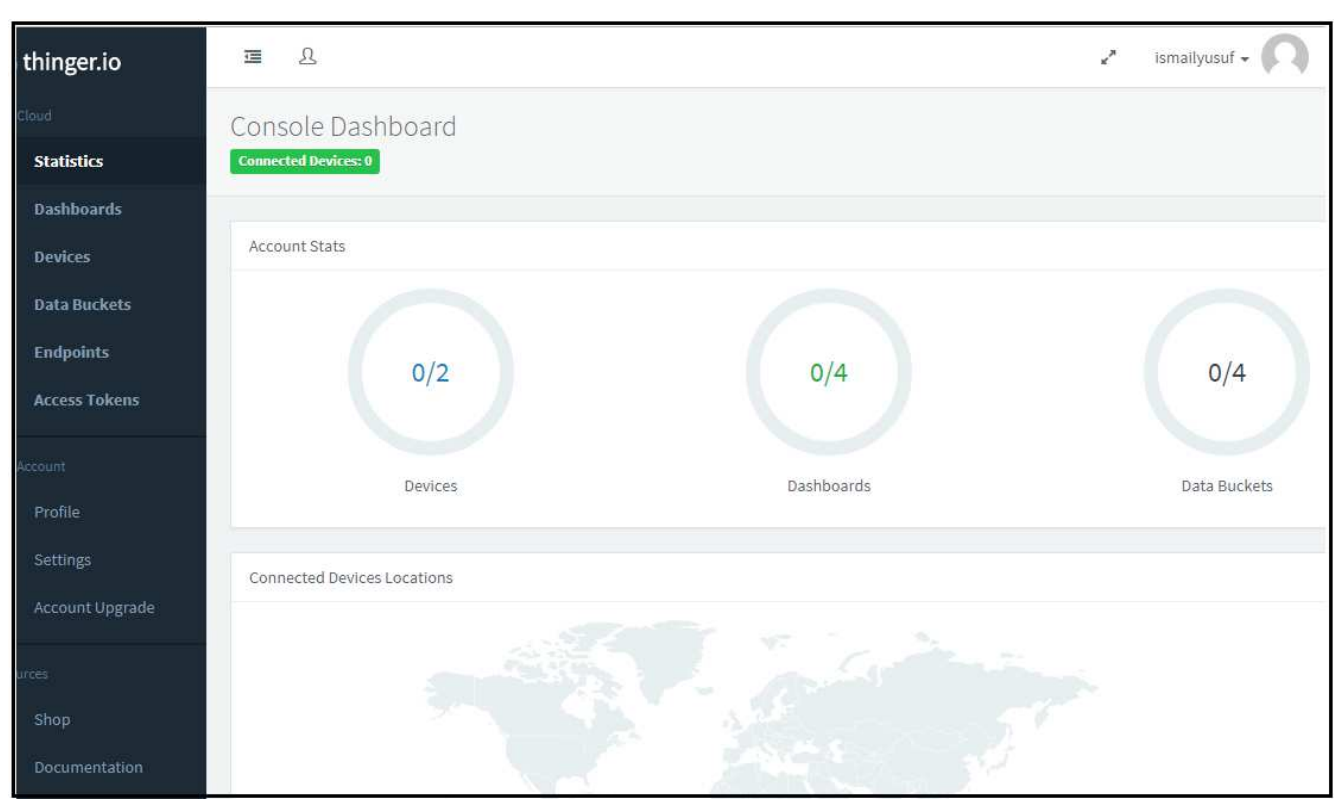

Fig. 17: Monitoring through thinger.Io

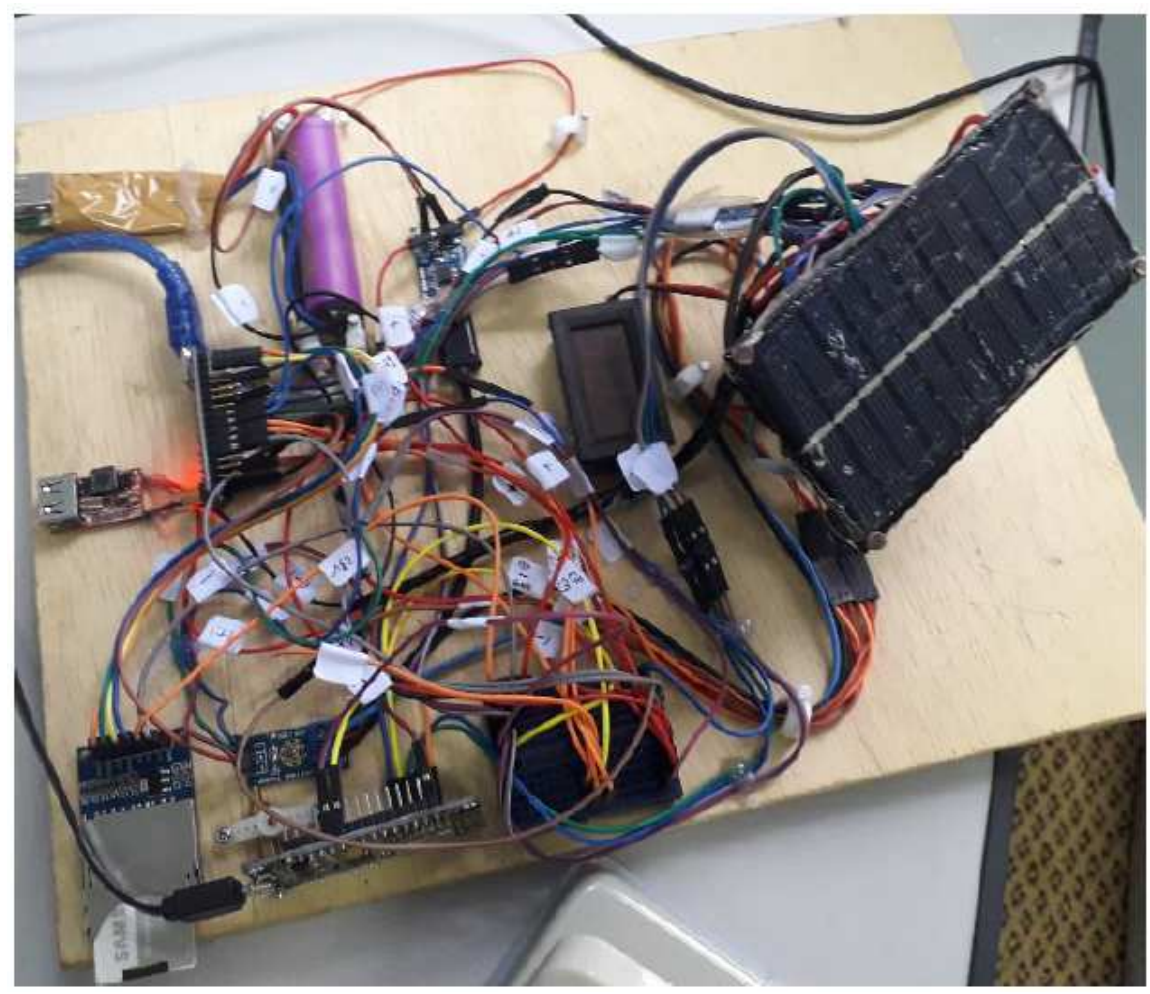

Fig. 18: Physical devices

\section{Result and Discussion}

\section{System Performance}

The Fig. 18 shows the physical form of the design results of the system, while the diagram block for testing process shown in Fig. 19. In this research, the hardware circuit consists of three parts, namely:

1. The first part is the series of Arduino, Battery and LCD that will be connected via a jumper cable. All three devices have an input of 5 volts. 
2. The second part is a series of solar tracking devices, consisting of two servo motors and a solar panel module.

3. The third part is the LCD circuit on the control board which serves to display the energy output absorbed by the solar panel, the better capacity received and the output of the energy used.

System testing is done to find out whether the system can function according to its function and can produce output as expected.

The first test is carried out on sensors and servo, where the data sent by the sensor is sent to servo to test each servo movement whether it has moved according to the procedure when it was executed. The next test is testing on an Appbased controller. Testing on the controller is done by entering certain angles according to the design results in the AppInventor. The controller test is followed by testing the database information that has been built at ThingerIo. The solar panel will be activated and the reading results will be viewed on the ThingerIo web using a mini LCD.
After the system is running properly and all parts function as desired, it will be followed by data retrieval of the temperature, voltage and light intensity of the solar panel.

\section{Tool Performance Testing}

Headings When the solar cell is illuminated by the sun it will produce energy (voltage). The magnitude of the voltage generated depends on the amount and intensity of the sun's rays on the solar cell and depends on the amount of solar cell used. The lighter that hits solar cell, the greater the voltage generated. Likewise, the opposite, the less sunlight intensity about solar cell, the voltage generated will decrease (during the cloudy or late afternoon). At night it is not exposed to sunlight so there is no voltage generated.

The reading of the data taken during the sunny days (days 1, 2 and 4) can be seen in Fig. 20, 21 and 22. When the weather is sunny, it can be seen that the temperature directly proportional to voltage and light intensity. In addition, the graphic shows a regular pattern.

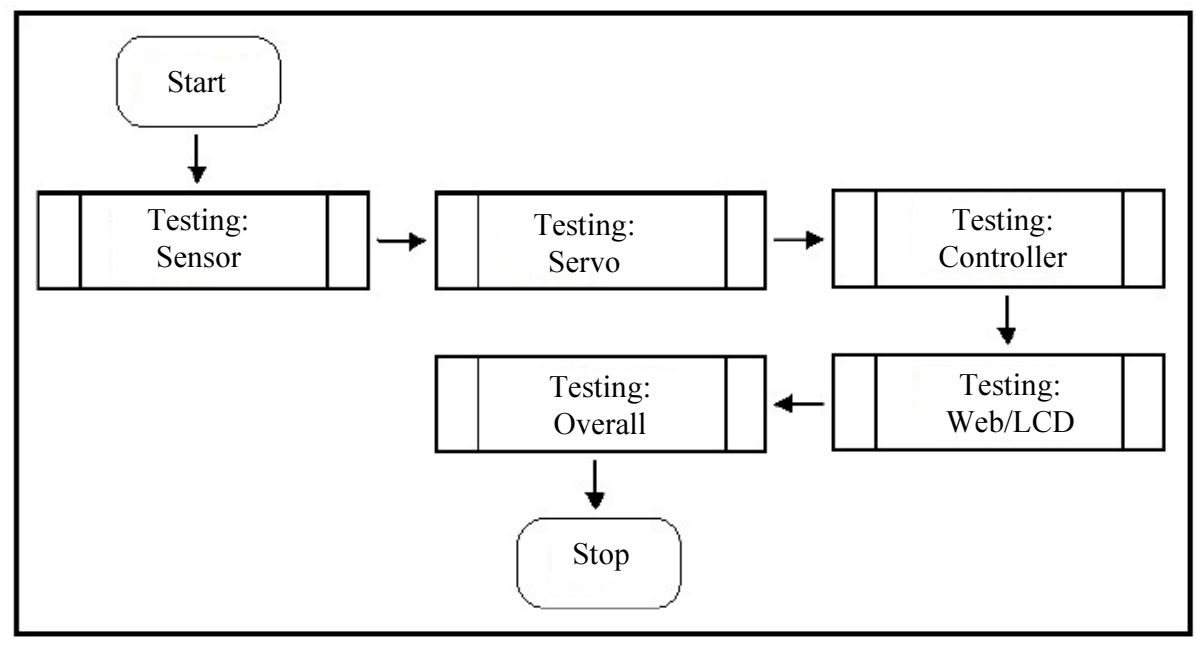

Fig. 19: Diagram block for testing process

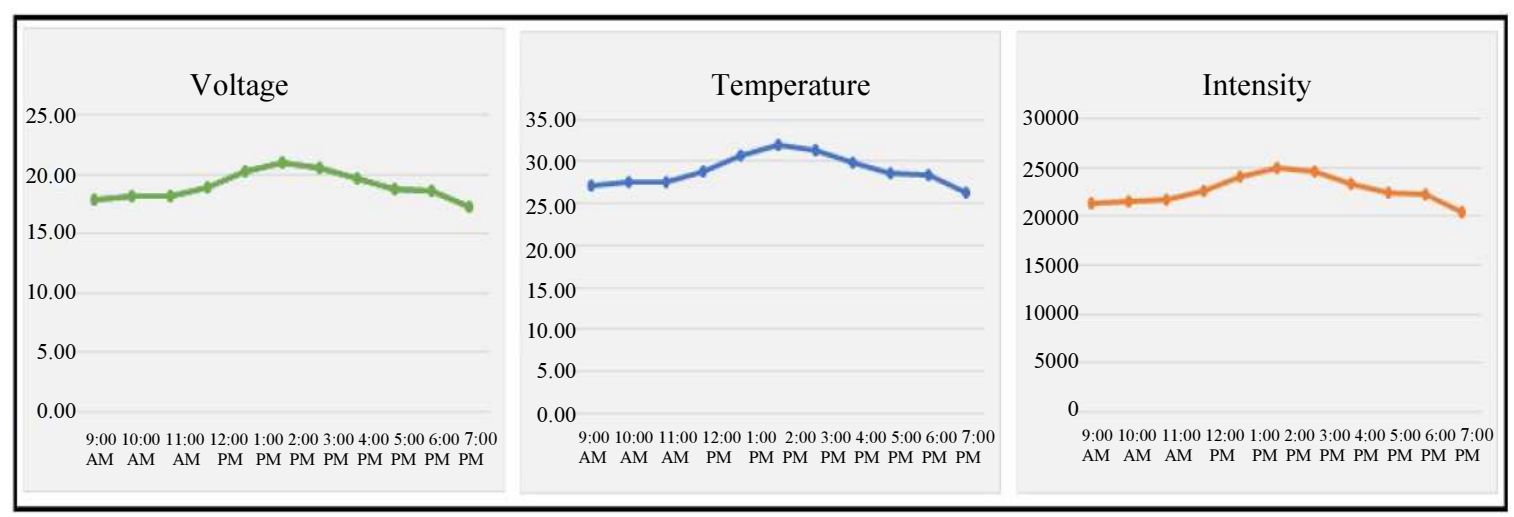

Fig. 20: Date taken: 1st day 


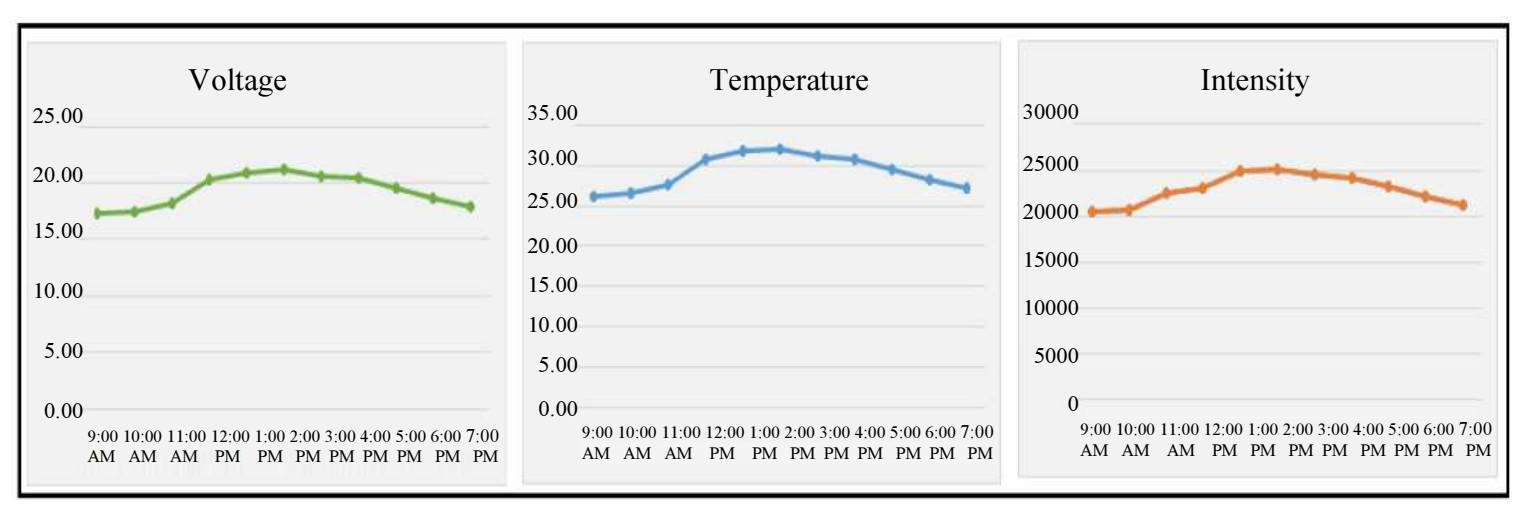

Fig. 21: Date taken: 2nd day

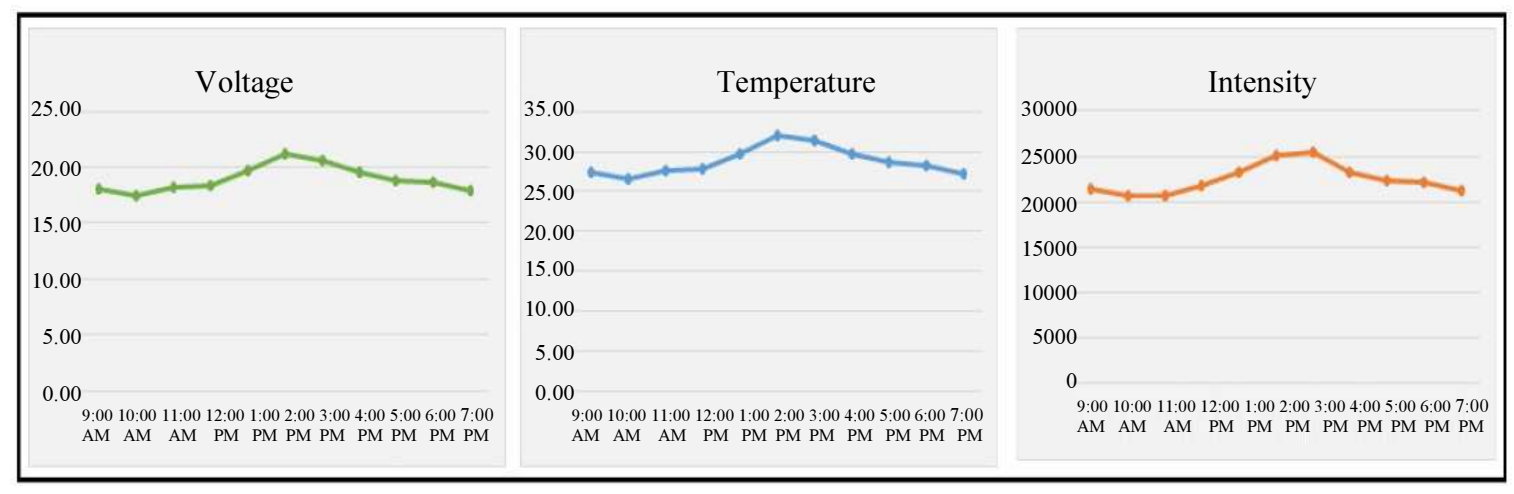

Fig. 22: Date taken: 4th day

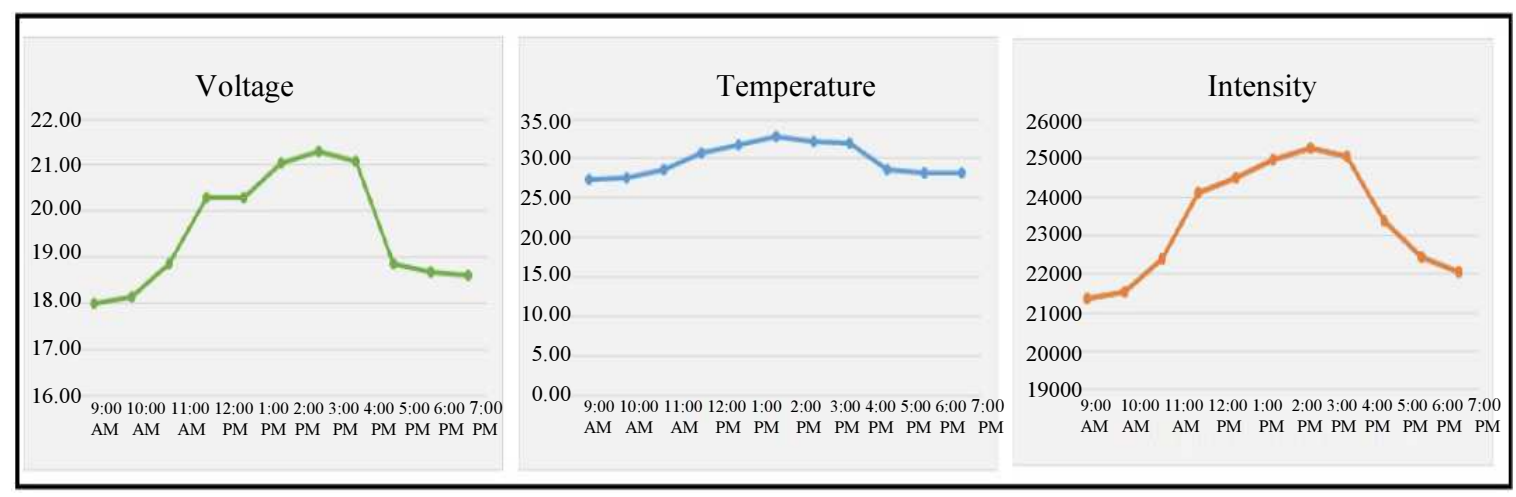

Fig. 23: Date taken: 3rd day

In the morning, the intensity of the light received by the solar panel will be maximum when directed to the position of 30 degrees from the rising sun. The servo moves horizontally and scans. At noon, the intensity of the light received by the solar panel will be maximum when it is directed to a position 90 degrees from the rising sun.

In the afternoon, the intensity of the light received by the solar panel will be maximum when directed to the position of 60 degrees from the rising sun.

The dual axis tracking system works optimally during the morning and evening. While during the day the Voltage produced in the solar tracker tends to be the same because the position of the sun is perpendicular to the solar cell.

When the sunny weather there is obtained, the average temperature is 29.50 , the average voltage is 19.40 Volt and the average light intensity is 23,187 Lux.

Figures 23 and 24 show the graph of temperature, voltage and light intensity during cloudy weather. When the weather is cloudy, the chart shows the voltage pattern and the intensity of the light which is directly proportional, but not the temperature graph. The motor will work heavier because the operator will always move it to find a certain angle that can produce maximum light intensity. 


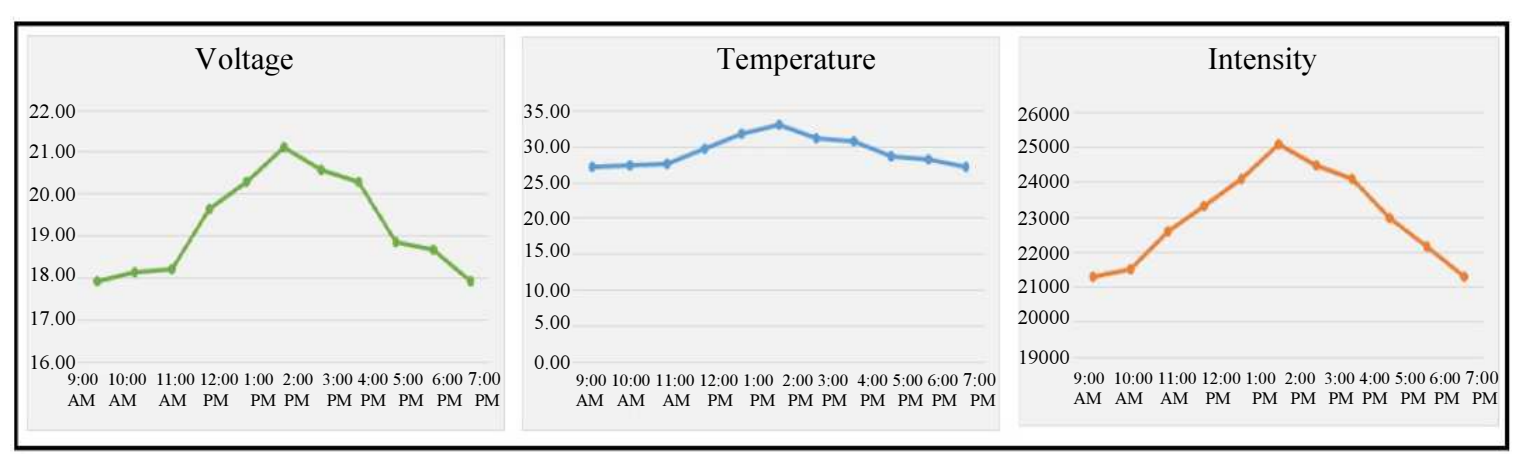

Fig. 24: Date taken: 5th day

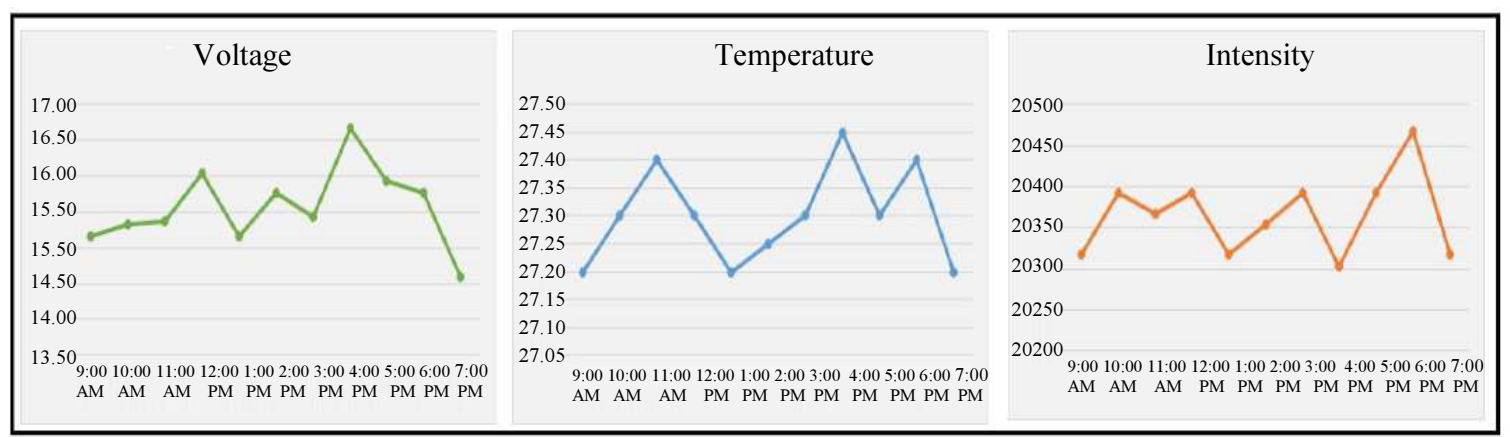

Fig. 25: Date taken: 6th

When the cloudy weather is obtained, the average temperature is 28.10 Celsius, the average voltage is 18.05 Volt and the average light intensity is 21,688 Lux.

Figure 25 shows the graph of temperature, voltage and light intensity during rainy weather. The graph shows the results of reading in a random pattern. Light intensity moves up and down sharply. This is because the intensity of the light received by the solar cell is very minimum even though the solar cell position has been changed.

When the rainy weather is obtained, the average temperature is 26.03 Celsius, the average voltage is 13.60 Volt and the average light intensity is 18,364 Lux.

\section{Conclusion}

The Some conclusions from this research are:

1. The use of AppInventor and ThingerIo is very helpful in maximizing device performance. AppInventor and ThingerIo make the connection between mechanical tools, mobile app-based controls and real-time data readings very close.

2. Dual axis sun tracker devices that are built using four LDRs produce an average voltage of 19.40 Volt when the sunny weather, 18.05 Volt when the cloudy weather and 13.60 Volt when the rainy weather.

3. In this research, it was found that the temperature is very influential on the amount of voltage produced. Where the temperature is directly proportional to the resulting voltage. Besides that, the temperature is influenced by the large intensity of sunlight absorbed by the sun tracker. When the sunny weather is obtained, the average temperature is 29.50 Celsius, the average voltage is 19.40 Volt and the light intensity is 23,187 Lux.

4. To maximize absorption of light intensity by the solar panel, the use of vertical axis and the horizontal axis is insufficient. Adding a Z-axis needs to be considered. While to reduce operator load, the use of an automatic solar tracker needs to be considered.

5. To maximize the absorption of sunlight, more research is needed on the harmonious relationship between the width of the solar cell, the tracker design and the motor strength.

6. Arduino is suitable to make a project related to hardware (mechanics) and Raspberry Pi is suitable to make a project that can deal with the internet directly (reading data in real time).

\section{Acknowledgement}

This research worked under grant LET-IT172/2017 issued by Dept. of Lamintang Computer College, Lamintang Education and Training Centre, Batam, KEPRI. Indonesia. Please do not hesitate to contact ismail.lamintang@yahoo.com for any questions related to the data, coding, commercialization and others. ismailyusuf.com https://sites.google.com/site/ism4ilyusuf 


\section{Author's Contributions}

Ismail Ismail Yusuf Panessai: Participated in all experiments, coordinated the data-analysis and contributed to the writing of the manuscript.

Muhammad Modi bin Lakulu: Coordinated the system (software).

Siva Kumar A/L Subramaniam: Contributed to the implementation of the system, and to the writing of the manuscript.

Ahmad Fadli Saad: Coordinated the data collection and contributed to the implementation of the system.

Muhd Ibrahim Muhamad Damanhuri: Contributed to the implementation of the system, data and analysis.

Nur Iksan Yusuf: Contributed to the software.

\section{Ethics}

This article is original and contains unpublished material. The corresponding author confirms that all of the other authors have read and approved the manuscript and no ethical issues involved.

\section{References}

Alexandru, C., 2013. A novel open-loop tracking strategy for photovoltaic systems. Scientific World J., 2013: 1-12.

Antolín, D., N. Medrano, B. Calvo and P.A. Martínez, 2017. A compact energy harvesting system for outdoor wireless sensor nodes based on a low-cost in situ photovoltaic panel characterization-modelling unit. Sensors, 17: 1794. DOI: 10.3390/s17081794

Barbose, G., S. Weaver and N. Darghouth, 2014. Tracking the sun VII: An historical summary of the installed price of photovoltaics in the United States from 1998 to 2013. Environmental Energy Technologies Division, Lawrence Berkeley National Laboratory.

Bradbury, K., R. Saboo, T.L. Johnson, J.M. Malof and A. Devarajan et al., 2016. Data descriptor: Distributed solar photovoltaic array location and extent dataset for remote sensing object identification. Scientific Data. DOI: 10.1038/sdata.2016.106

Bryan, A., B. Eason, R. Giffin and S. Rauchfuss, 2011. Alternative solar energy generation. University of Central Florida.

Horan, B., 2013. Practical Raspberry Pi. Apress.

Lee, C.D., H.C. Huang and H.Y. Yeh, 2013. The development of sun-tracking system using image processing. Sensors, 13: 5448-5459.

DOI: $10.3390 / \mathrm{s} 130505448$
Lee, C.Y., P.C. Chou, C.M. Chiang and C.F. Lin, 2009. Sun tracking systems: A review. Sensors, 9: 3875-3890. DOI: 10.3390/s90503875

Merlaud, A., M.D. Mazi 'ere, C. Hermans and A. Cornet, 2012. Equations for solar tracking. Sensors, 12: 4074-090. DOI: 10.3390/s120404074

Ranabhat, K., L. Patrikeev, A.A. Revina, K. Andrianov and V. Lapshinsky et al., 2016. An introduction to solar cell technology. J. Applied Engineering Sci., DOI: $10.5937 /$ jaes 14-10879

Rodr'1guez-Canosa, G., J.D. Cerro Giner and A. Barrientos, 2014. Detection and tracking of dynamic objects by using a multirobot system: Application to critical infrastructures surveillance. Sensors, 14: 2911-2943. DOI: $10.3390 / \mathrm{s} 140202911$

Rufino, G. and M. Grassi, 2009. Multi-aperture CMOS sun sensor for microsatellite attitude determination. Sensors, 9: 4503-4524. DOI: 10.3390/s90604503

Samrat, N.H., N. Ahmad, I.A. Choudhury and Z. Taha, 2014. Modeling, control and simulation of battery storage photovoltaic-wave energy hybrid renewable power generation systems for island electrification in Malaysia. Scientific World J., 2014: 1-21.

Scott, R., 2015. Arduino: Arduino user guide for operating system, programming, projects and more. SS Publishing.

Skouri, S., A.B. Haj Ali, S. Bouadila, M.B. Salah and S.B. Nasrallah, 2016. Design and construction of sun tracking systems for solar parabolic concentrator displacement. Renewable Sustainable Energy Revi., 60: 1419-429.

Tharamuttam, J.K. and A.K. Ng, 2017. Assessing the feasibility of using the heat demand-outdoor temperature function for a long-term district heat demand forecast. Energy Procedia, 143: 629-634.

Upton, E., 2015. Raspberry Pi: User Guide. Gareth Halfacree.

Wang, J.M. and C.L. Lu, 2013. Design and implementation of a sun tracker with a dual-axis single motor for an optical sensor-based photovoltaic system. Sensors, 13: 3157-3168.

Zhu, N. and H. Zhao, 2018. IoT Applications in the ecological industry chain from information security and smart city perspectives. Computers Electrical Engineering, 65: 34-43. 